\title{
Analysis of Unidirectional Secondary Resonant Single Active Bridge DC-DC Converter
}

\author{
Cao Anh Tuan * and Takaharu Takeshita
}

Citation: Tuan, C.A.; Takeshita, T. Analysis of Unidirectional Secondary Resonant Single Active Bridge DC-DC Converter. Energies 2021, 14, 6349. https://doi.org/10.3390/ en14196349

Academic Editor: Tibor Vince

Received: 10 September 2021 Accepted: 29 September 2021 Published: 5 October 2021

Publisher's Note: MDPI stays neutral with regard to jurisdictional claims in published maps and institutional affiliations.

Copyright: (c) 2021 by the authors. Licensee MDPI, Basel, Switzerland. This article is an open access article distributed under the terms and conditions of the Creative Commons Attribution (CC BY) license (https:// creativecommons.org/licenses/by/ $4.0 /)$.
Electrical and Mechanical Engineering Department, Nagoya Institute of Technology, Gokiso-cho, Showa-ku, Nagoya 466-8555, Japan; take@nitech.ac.jp

* Correspondence: t.cao.936@stn.nitech.ac.jp

Abstract: A compact and highly efficient unidirectional DC-DC converter is required as a battery charger for electrical vehicles, which will rapidly become widespread in the near future. The single active bridge (SAB) converter is proposed as a simple and high-frequency isolated unidirectional converter, which is comprised of an active H-bridge converter in the primary side, an isolated high frequency transformer, and a rectifying secondary diode bridge output circuit. This paper presents a novel, unidirectional, high-frequency isolated DC-DC converter called a Secondary Resonant Single Active Bridge (SR-SAB) DC-DC converter. The circuit topology of the SR-SAB converter is a resonant capacitor connected to each diode in parallel in order to construct the series resonant circuit in the secondary circuit. As a result, the SR-SAB converter achieves a higher total power factor at the high frequency transformer and a unity voltage conversion ratio under the unity transformer turns ratio. Small and nonsignificant overshoot values of current and voltage waveforms are observed. Soft-switching commutations of the primary H-bridge circuit and the soft recovery of secondary diode bridge are achieved. The operating philosophy and design method of the proposed converter are presented. Output power control using transformer frequency variation is proposed. The effectiveness of the SR-SAB converter was verified by experiments using a $1 \mathrm{~kW}, 48 \mathrm{VDC}$, and $20 \mathrm{kHz}$ laboratory prototype.

Keywords: secondary resonant single active bridge (SR-SAB) converter; battery charger; DC-DC converter; isolated converter; soft switching; unidirectional converter

\section{Introduction}

In 1991, the isolated bidirectional DC-DC converter, which adopts the dual-activebridge (DAB) configuration and uses a soft-switching technique to achieve high efficiency, was proposed [1]. The transferred power of the DAB converter is regulated by the induced voltage drop on the inductor produced by the relative position of different phase shift angles between the primary and secondary transformer AC voltages. The soft-switching pattern of the DAB converter was resolved during this process [2]. The DAB converter achieved a high total power factor (TPF) at the high frequency transformer and a unity voltage conversion ratio under the unity transformer turns ratio. Many papers related to DAB converters have been published [3]. Papers on the soft-switching control method in the low power supply range [4,5] and the utilization of GaN FETs to construct highefficiency converters [6] have also been published. In an additional study, a DAB converter was applied to an LED driver [7].

Several circuit topologies of unidirectional isolated DC-DC converters have been proposed for their application in battery chargers. One unidirectional topology based on the DAB converter is a configuration in which two switches in the secondary H-bridge converter are replaced with diodes. For wide-range operation, three operation modes of boost, buck-boost, and buck are proposed [8]. The light-load conversion efficiency was improved significantly by using the proposed control strategy [9]. 
The unidirectional configuration, with the diode rectifier circuit adding the choke coil in the secondary circuit, can obtain high efficiency [10]. The topology achieved a high TPF at the high-frequency transformer and a unity voltage conversion ratio under the unity transformer turns ratio. However, a voltage surge occurred, owing to the resonance between the transformer leakage inductance and the inherent parasitic capacitance associated with the secondary diodes. To suppress the voltage surge, an RCD snubber circuit was installed at the output of the diode bridge rectifier circuit [11]. A hybrid-switching converter was then proposed to achieve minimal voltage stress of the diode bridge rectifier circuit [12].

Another unidirectional topology of an SAB converter is a simpler configuration in which the secondary $\mathrm{H}$-bridge of the DAB converter is replaced with a diode bridge rectifier circuit. When this was trialed, the SAB converter achieved soft switching in the same way as the DAB converter [13]. The partial resonant SAB converter, in which a capacitor is connected to each primary switch in parallel, was proposed to reduce the peak current and conduction loss [14]. By utilizing SiC switching devices in DC-DC circuits, high-efficiency performance was achieved [15]. Papers on the application of the SAB converter to the wind turbine converter were published [16,17]. However, the SAB converter does not operate at the unity voltage conversion ratio. Therefore, the DC voltage conversion ratio and the total power factor of the transformer in the SAB converter were low [1].

This paper presents a novel, unidirectional, high-frequency isolated DC-DC converter called a secondary resonant single active bridge (SR-SAB) DC-DC converter, as shown in Figure 1 [18]. In the SR-SAB DC-DC converter, a resonant capacitor $C_{r}$ is connected in parallel to each diode in the secondary rectifying diode circuit of the $S A B$ converter. $A$ trapezoidal transformer current waveform, similar to that of a DAB converter, is obtained because the transformer current sign at the zero-crossing region is softly switched by the series resonance between the transformer leakage inductance $L$ and the resonant capacitors $C_{r}$ of the secondary diodes. As a result, the SR-SAB converter reaches the unity DC voltage conversion ratio and improves the total power factor of the transformer compared with the SAB converter. The behavior and design of the proposed SR-SAB converter will be explained. The transformer frequency which is equal to the switching frequency can be independently selected at a frequency lower than the resonant frequency. The leakage inductance can be designed to be sufficiently small enough to be incorporated into the high-frequency transformer. The output power can be adjusted over a wide range by controlling the transformer frequency.

The effectiveness of the proposed converter is verified through experiments using a $1 \mathrm{~kW}, 48 \mathrm{~V}$, and $20 \mathrm{kHz}$ rating laboratory prototype.

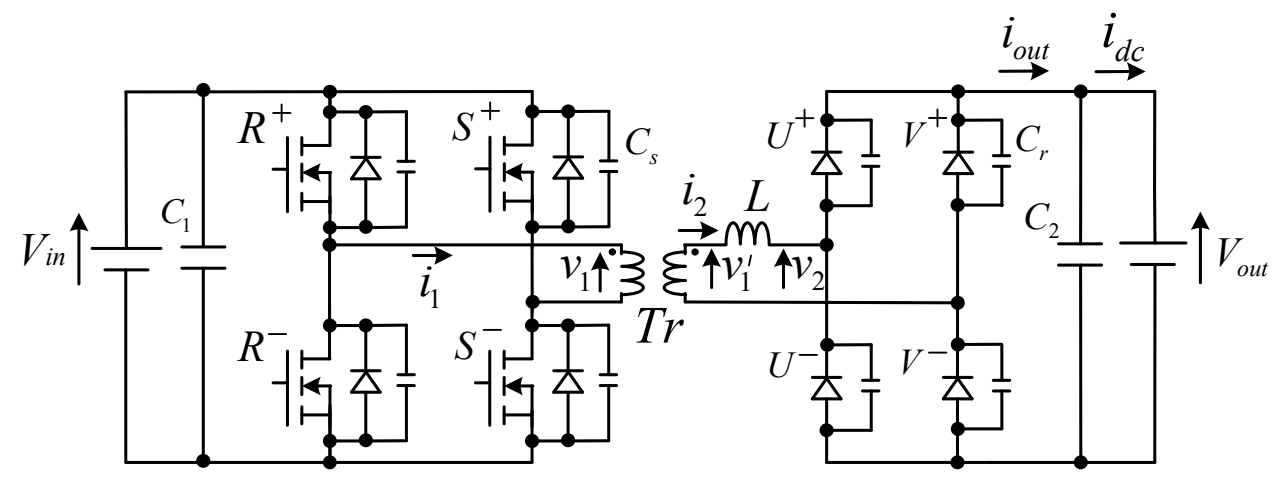

Figure 1. Proposed unidirectional secondary resonant single active bridge (SR-SAB) DC-DC converter circuit.

\section{Conventional SAB DC-DC Converter}

Figure 2 shows the conventional SAB DC-DC converter. In the circuit configuration of Figure 2a, the SAB converter is comprised of a primary H-bridge converter, an isolated high-frequency transformer, and a secondary rectifying diode bridge circuit. The 
primary H-bridge converter is constructed from four switches, $R^{+}-S^{-}$, with the small soft-switching capacitor $C_{S}$ in parallel. The leakage inductance $L$ of the transformer is expressed as the equilavent leakage inductance converted to the secondary side. By denoting the number of turns of the transformer's primary coil with $N_{1}$, and the number of turns of the transformer's secondary coil with $N_{2}$, the turns ratio can be expressed as $a=N_{1} / N_{2}$. Figure $2 \mathrm{~b}$ shows the secondary equivalent circuit. The primary voltage component $v_{1}^{\prime}\left(=v_{1} / a\right)$, which transfers the primary voltage $v_{1}$ to the secondary side, is represented as the voltage across the secondary magnetizing inductance of the transformer.

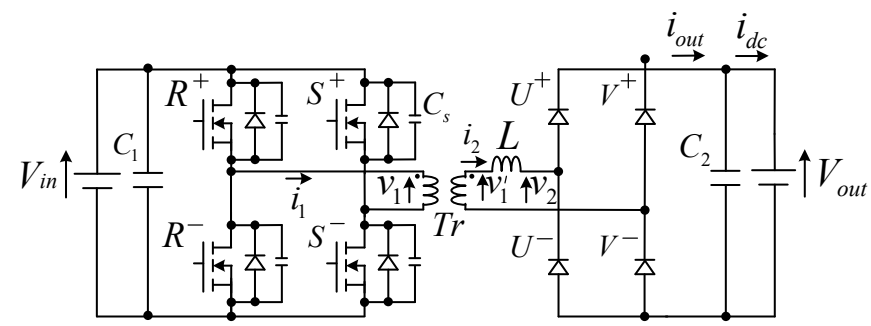

(a) Circuit configuration

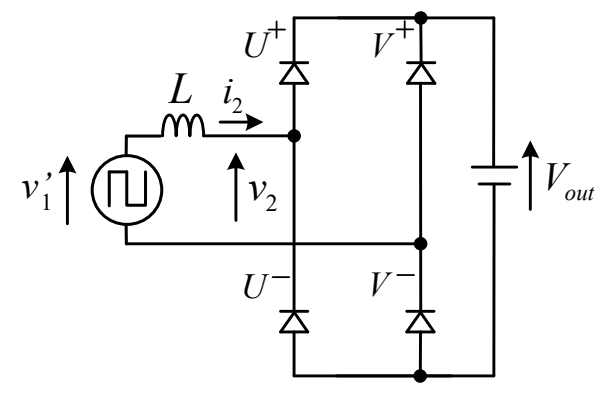

(b) Secondary equivalent circuit

Figure 2. Conventional SAB DC-DC converter.

Figure 3 shows the voltage and current operation waveforms of the transformer in the steady state of the conventional unidirectional SAB converter. The conditions of the waveforms are presented at a unity turns ratio of $a=1$ for the isolated transformer while neglecting the transformer magnetizing current. The primary H-bridge converter generates a square AC voltage $v_{1}\left(=v_{1}{ }^{\prime}\right)$ with the amplitude of the input DC voltage $V_{i n}$, and frequency $f_{s}\left(=1 / 2 T_{S}\right)$ by controlling the switches $R^{+}-S^{-}$with a 50 percent duty cycle. If the amplitude $V_{i n}$ of the primary voltage $v_{1}{ }^{\prime}$ is equal to the output DC voltage $V_{\text {out }}$ in Figure 3, the secondary diodes $U^{+}-V^{-}$cannot be turned on, and no power is sent to the secondary side in the SAB converter. Therefore, the SAB converter does not work at a unity DC voltage conversion ratio $M_{v}=V_{\text {out }} / V_{\text {in }}=1$. In the voltage waveforms in Figure 3, the amplitude $V_{\text {in }}$ of the primary voltage $v_{1}{ }^{\prime}$ is higher than the output DC voltage $V_{\text {out }}$. The transformer currents $i_{1}$ and $i_{2}$ flow because of the difference in voltage between the primary voltage $v_{1}{ }^{\prime}$ and the output DC voltage $V_{\text {out }}$. 


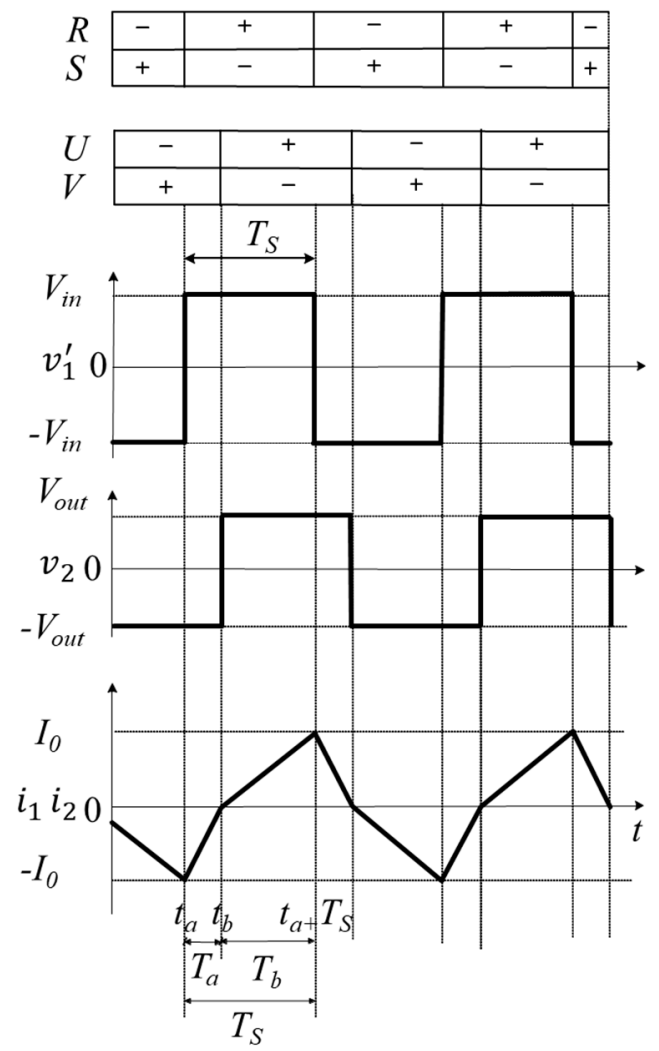

Figure 3. Voltage and current operation waveforms of conventional SAB DC-DC converter.

The analytical transformer current $i_{2}$ in the positive half period $T_{S}$ of primary voltage $v_{1}^{\prime}$ is derived. From Figure $2 b$, the following voltage equation is obtained:

$$
v_{1}^{\prime}=L \frac{d i_{2}}{d t}+v_{2}
$$

In the duration $T_{a}\left(t_{a} \leq t \leq t_{b}\right)$, the primary voltage $v_{1}^{\prime}$ in Figure 3 is larger than the output DC voltage $V_{\text {out }}$ and the negative transformer current $i_{2}$ flows. The diodes $U^{-}$ and $V^{+}$are in the on-state. Substituting $v_{1}^{\prime}=V_{\text {in }}, v_{2}=-V_{\text {out }}$, and the initial current $i_{2}\left(t_{a}\right)=-I_{o}$ into (1), the secondary current $i_{2}(t)$ in the duration $T_{a}$ is obtained as follows:

$$
i_{2}(t)=\frac{V_{\text {in }}+V_{\text {out }}}{L}\left(t-t_{a}\right)-I_{o}\left(t_{a} \leq t \leq t_{b}\right)
$$

Because the secondary current $i_{2}\left(t_{\mathrm{b}}\right)=0$ in (2), the duration $T_{a}$ is obtained in (3):

$$
T_{a}=t_{b}-t_{a}=L \frac{I_{o}}{V_{\text {in }}+V_{\text {out }}}
$$

In the duration $T_{b}\left(t_{b} \leq t \leq t_{a}+T_{s}\right)$, the positive transformer current $i_{2}$ flows and the diodes $U^{+}$and $V^{-}$are in the on-state. Substituting $v_{1}^{\prime}=V_{\text {in }}$ and $v_{2}=V_{\text {out }}$ into (1), the secondary current $i_{2}(t)$ in the duration $T_{b}$ is obtained as follows:

$$
i_{2}(t)=\frac{V_{\text {in }}-V_{\text {out }}}{L}\left(t-t_{b}\right)\left(t_{b} \leq t \leq t_{a}+T_{S}\right)
$$

The duration $T_{b}$ is expressed using (3) in (5):

$$
T_{b}=T_{s}-T_{a}=T_{s}-L \frac{I_{o}}{V_{\text {in }}+V_{\text {out }}}
$$


Because the secondary current $i_{2}\left(t_{a}+T_{s}\right)=I_{0}$ in (4), the peak current $I_{0}$ is solved as follows:

$$
\begin{gathered}
i_{2}\left(t_{a}+T_{S}\right)=\frac{V_{\text {in }}-V_{\text {out }}}{L}\left(T-L \frac{I_{o}}{V_{\text {in }}+V_{\text {out }}}\right)=I_{O} \\
I_{0}=\frac{V_{\text {in }}^{2}-V_{\text {out }}^{2}}{2 L V_{\text {in }}} T_{S}
\end{gathered}
$$

Substituting $I_{o}$ in Figure 3 into Equations (3) and (5), the durations $T_{a}$ and $T_{b}$ are obtained as follows:

$$
\begin{aligned}
& T_{a}=\frac{V_{\text {in }}-V_{\text {out }}}{2 V_{\text {in }}} T_{S} \\
& T_{b}=\frac{V_{\text {in }}+V_{\text {out }}}{2 V_{\text {in }}} T_{S}
\end{aligned}
$$

The total power factor TPF of the primary side is defined in (9) by using the output power $P_{\text {out }}$ and the effective values of voltage $V_{1}$ and current $I_{1}$ :

$$
T P F=\frac{P_{\text {out }}}{V_{1} I_{1}}
$$

The output power $P_{\text {out }}$ can be calculated using the following equation:

$$
P_{\text {out }}=\frac{1}{T_{s}} \int_{t_{a}}^{t_{a}+T_{s}} V_{\text {out }} i_{2} d t=\frac{\left(V_{\text {in }}^{2}-V_{\text {out }}^{2}\right) V_{\text {out }} T_{s}}{4 L V_{\text {in }}} .
$$

The effective value of primary current $I_{1}$ is calculated as follows:

$$
I_{1}=\frac{1}{\sqrt{3}} I_{o}=\frac{1}{\sqrt{3}} \frac{V_{\text {in }}^{2}-V_{\text {out }}^{2}}{2 L V_{\text {in }}} T_{S}
$$

Substituting (10), (11), and the effective values of primary voltage $V_{1}=V_{\text {in }}$ into (9), the total power factor TPF is obtained as follows:

$$
T P F=\frac{\sqrt{3} V_{\text {out }}}{2 V_{\text {in }}}
$$

A design example of the conventional SAB and proposed SR-SAB converters are explained. Table 1 shows the common specifications of the converter set at $P_{\text {out }}=1.0 \mathrm{~kW}$, $V_{\text {out }}=48 \mathrm{~V}$, and $f_{s}=20 \mathrm{kHz}$. Table 2 shows the comparisons of calculated characteristics between the conventional and proposed converters. In the conventional converter, the input DC voltage $V_{\text {in }}=62.5 \mathrm{~V}$, the voltage conversion ratio $M_{v}=V_{\text {out }} / V_{\text {in }}=1.30$, the peek current $I_{0}=41.7 \mathrm{~A}$, and the total power factor $T P F=0.66$. The characteristics of the proposed SR-SAB converter in Table 2, which are derived from the theory in Section 4, improves significantly compared with those of the conventional converter.

Table 1. Common specifications for conventional SAB and proposed SR-SAB converters on $1 \mathrm{~kW}$ output power.

\begin{tabular}{cc}
\hline Output power $P_{\text {out }}$ & $1.0 \mathrm{~kW}$ \\
Output voltage $V_{\text {out }}$ & $48 \mathrm{~V}$ \\
Turns ratio $a$ & 1 \\
Leakage inductance $L$ & $7.7 \mu \mathrm{H}$ \\
Transformer frequency $f_{s}$ & $20 \mathrm{kHz}$ \\
\hline
\end{tabular}


Table 2. Comparisons of characteristics between conventional SAB and proposed SR-SAB converters on $1 \mathrm{~kW}$ output power.

\begin{tabular}{ccc}
\hline Converter & SAB & SR-SAB \\
\hline Input voltage $V_{\text {in }}$ & $62.5 \mathrm{~V}$ & $48.0 \mathrm{~V}$ \\
Voltage conversion ratio $M_{v}$ & 1.30 & 1.00 \\
Peek current & $41.7 \mathrm{~A}$ & $25.0 \mathrm{~A}$ \\
Effective current value $I_{1}$ & $24.1 \mathrm{~A}$ & $23.5 \mathrm{~A}$ \\
Total power factor $T P F$ & 0.66 & 0.89 \\
Resonant capacitor $C_{r}$ & - & $0.52 \mu \mathrm{F}$ \\
\hline
\end{tabular}

\section{Unidirectional Secondary Resonant Single Active Bridge (SR-SAB) \\ DC-DC Converter}

\subsection{Main Circuit Configuration and Behavior}

The circuit configuration of the proposed unidirectional SR-SAB DC-DC converter in Figure 1 adds the resonant capacitor $C_{r}$ in parallel with the secondary diodes $U^{+}-V^{-}$ in the conventional SAB converter shown in Figure 2. Figure 4 shows the voltage and current operation waveforms of the transformer as it corresponds to the proposed SR-SAB converter given the condition that the unity turns ratio $a=1$ for the high-frequency transformer while neglecting the transformer magnetizing current. The SR-SAB converter achieves the unity input and output voltage conversion ratio $M_{v}=1\left(V_{\text {in }}=V_{\text {out }}\right)$.

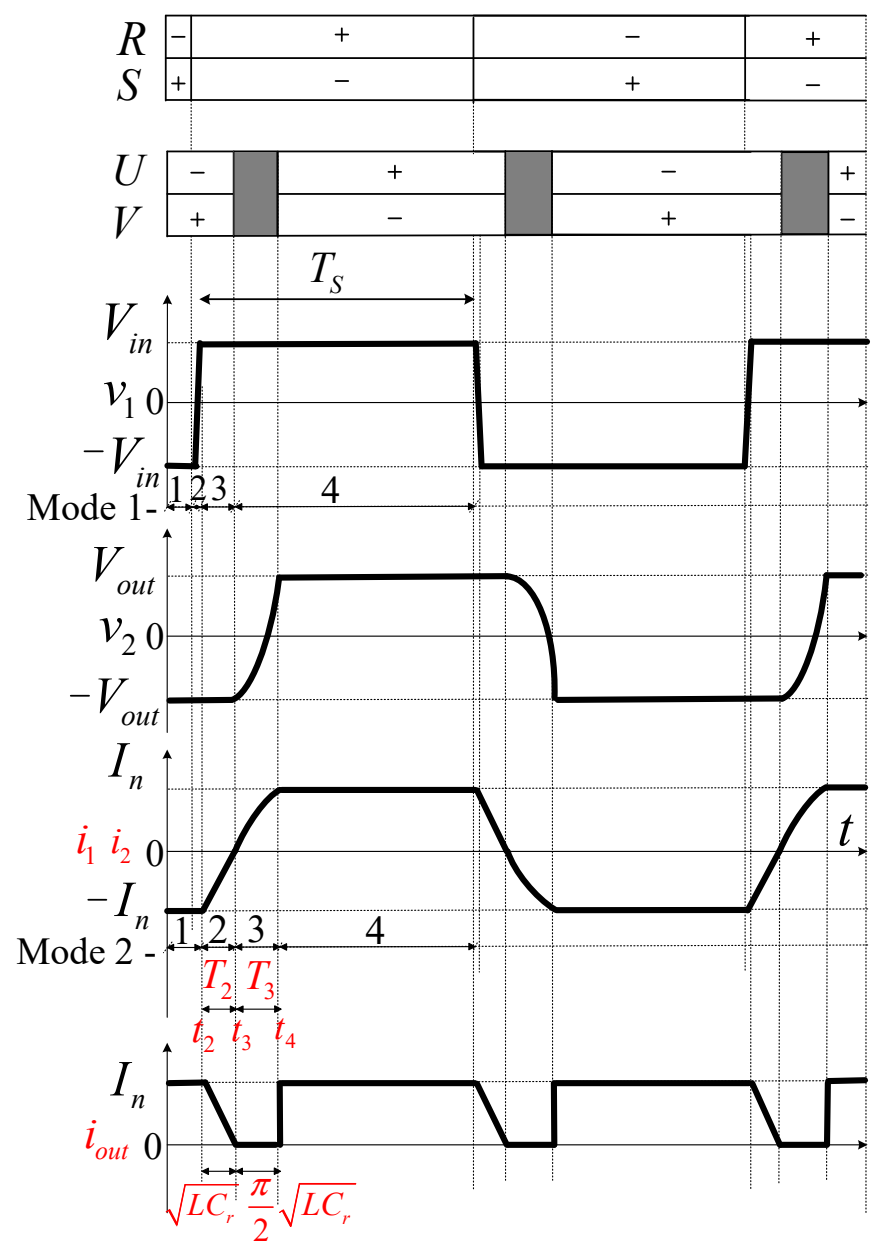

Figure 4. Voltage and current operation waveforms of the proposed SR-SAB DC-DC converter.

The primary $\mathrm{H}$-bridge converter produces the rectangular AC voltage $v_{1}$ with the amplitude $V_{i n}$ and switching frequency $f_{s}\left(=1 / 2 T_{s}\right)$ by alternately switching the switches 
$R^{+}-S^{-}$with a 50 percent duty cycle. The secondary voltage $v_{2}$ with the rectangular waveform lagged by the primary voltage $v_{1}$ is obtained. The magnetizing current is very small and neglected, leading to the production of the identical trapezoidal current waveforms for the primary current as well as the secondary current. The rectified current $i_{\text {out }}$ flows according to the conditions of the on-state diodes.

\subsection{Soft-Switching Commutation of Primary Converter}

The primary converter achieves soft switching in all commutations. Figure 5 shows the soft-switching modes of the primary H-bridge converter from $R^{-}$and $S^{+}$switches to $R^{+}$and $S^{-}$switches.
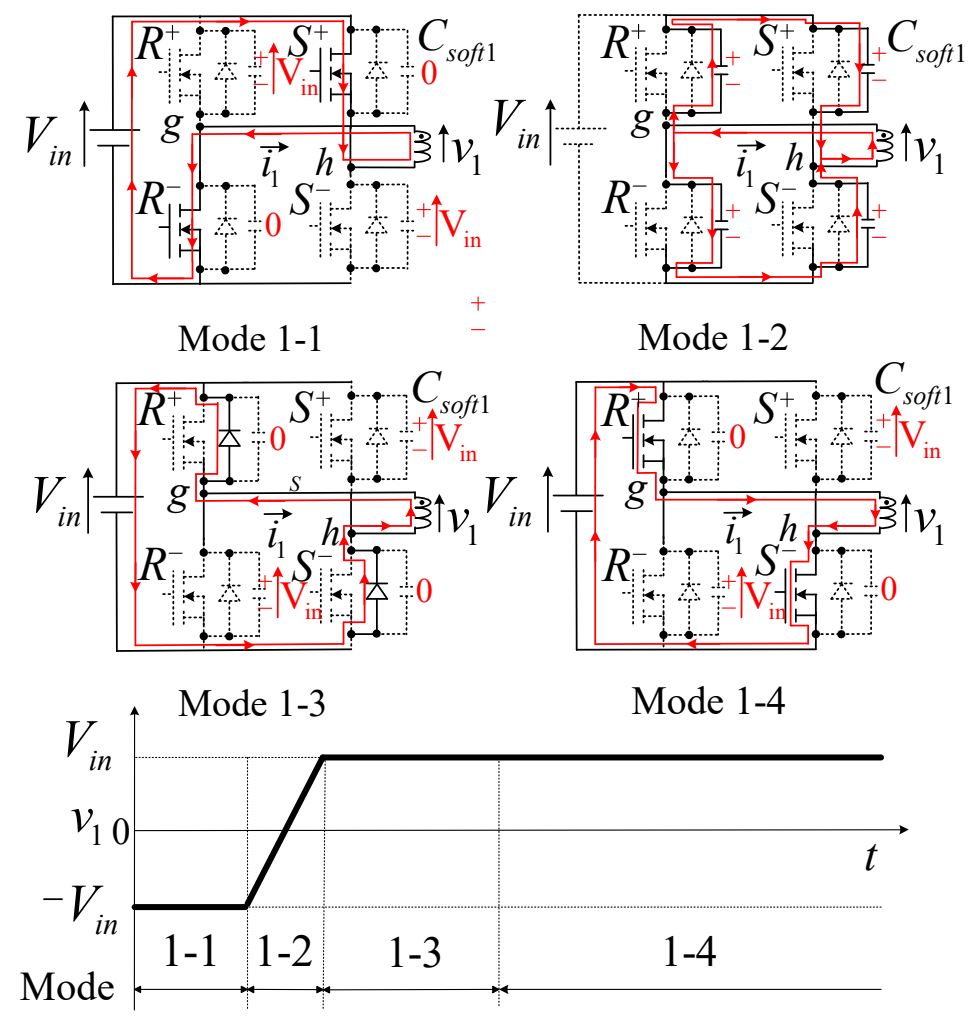

Figure 5. Soft-switching operation modes of the primary H-bridge switches circuit.

In Mode $1-1, R^{-}$and $S^{+}$switches are in the turn-on state, generating the primary voltage $v_{1}$ of $-V_{i n}$. Primary current $i_{1}$ with negative value $-I_{n}$ is conducted through $R^{-}$ and $S^{+}$switches. The voltages on the parallel capacitors of $R^{-}$and $S^{+}$switches are kept at zero. When $R^{-}$and $S^{+}$switches are changed to the turn-off state, zero voltage switching (ZVS) of $R^{-}$and $S^{+}$switches is obtained because the voltage of the parallel capacitors are zero. After that, the circuit changes to Mode 1-2.

In Mode $1-2$, the primary current $i_{1}$ with the negative value $-I_{n}$ starts to flow through the four capacitors. The voltage of the parallel capacitors $C_{s}$ of $R^{-}$and $S^{+}$switches increases, and the voltage of the parallel capacitors $C_{S}$ of $R^{+}$and $S^{-}$switches decreases. The primary voltage $v_{1}$ interchanges from $-V_{i n}$ to $V_{i n}$. When the voltages on parallel capacitor $C_{S}$ of $R^{+}$and $S^{-}$switches is reduced to zero, the anti-parallel diodes on $R^{+}$and $S^{-}$switches are switched to the turn-on state and start conducting. After that, the circuit changes to Mode 1-3.

In Mode 1-3, the switching-on gate signals for $R^{+}$and $S^{-}$switches are given, leading the primary current $i_{1}$ to increase continuously toward zero. When the sign of the primary current $i_{1}$ changes to positive, the circuit changes to Mode $1-4$.

In Mode $1-4, R^{+}$and $S^{-}$switches are changed to the on-state by zero-voltage switching because of the zero voltage of the parallel capacitor. 


\subsection{Operation Analysis of Secondary Diode Rectifier Circuit}

Figure 6 shows the commutation modes in the secondary side of the diode rectifying circuit, swapping between the pair of diodes $U^{-}$and $V^{+}$and the pair of diodes $U^{+}$and $V^{-}$under the unity input and output voltage conversion ratio $M_{v}=1\left(V_{\text {in }}=V_{\text {out }}\right)$.
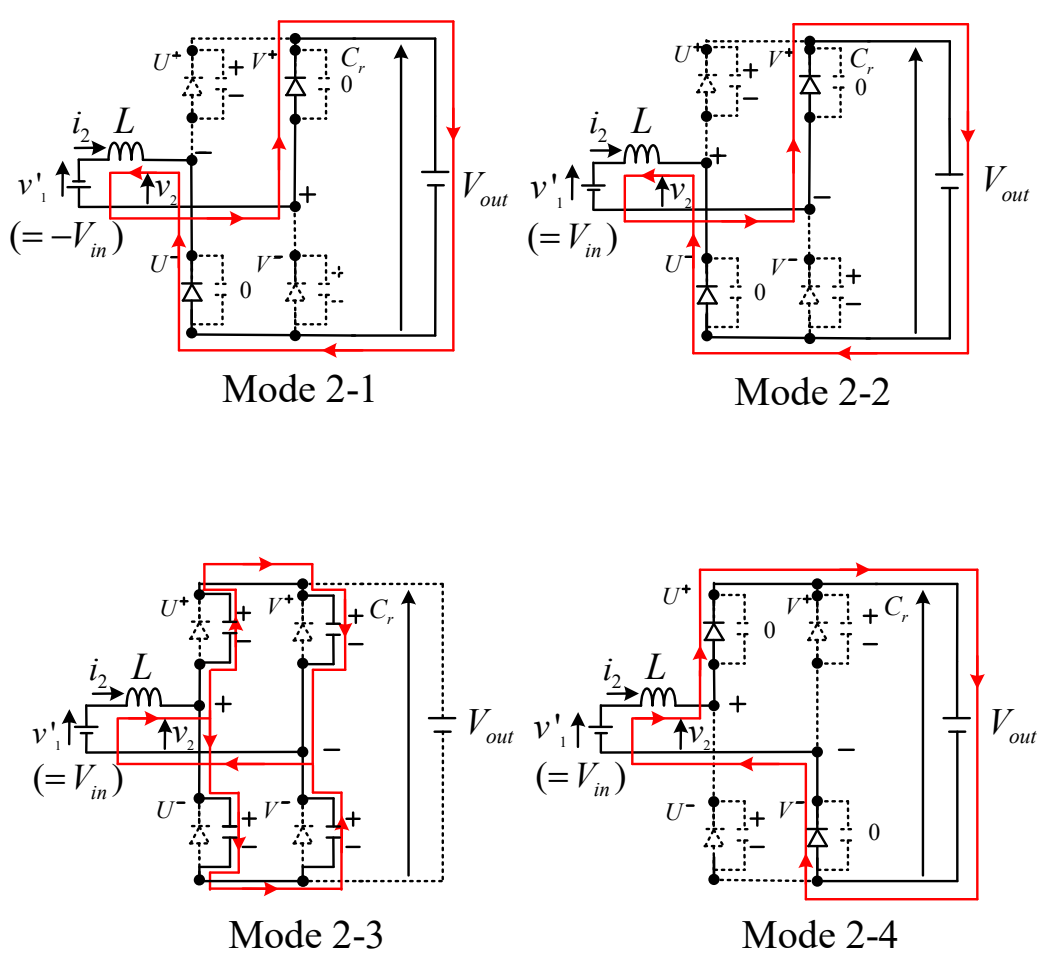

Figure 6. Commutations of the secondary diode rectifier circuit.

In Mode 2-1, the primary voltage $v_{1}^{\prime}\left(=V_{1} / a\right)$ of $-V_{\text {in }}\left(=-V_{\text {out }}\right)$ is generated, and the secondary current $i_{2}$ with negative value $-I_{n}$ flows though the pair of diodes $U^{-}$and $V^{+}$. The voltages on parallel capacitors $C_{r}$ of diodes $U^{-}$and $V^{+}$are both zero, and the voltages on parallel capacitors $C_{r}$ of diodes $U^{+}$and $V^{-}$are fully charged to the value $V_{\text {out }}$ of output voltage. When the value of primary voltage $v_{1}^{\prime}$ changes from $-V_{\text {in }}$ to $V_{\text {in }}\left(=V_{\text {out }}\right)$ at the time $\mathrm{t}=\mathrm{t}_{2}$, the circuit starts to enter Mode 2-2.

In Mode 2-2, within the duration $t_{2} \leq t \leq t_{3}$, the primary voltage $v_{1}^{\prime}$ changes to the positive value $V_{\text {in }}\left(=V_{\text {out }}\right)$. The diodes $U^{-}$and $V^{+}$remain on-state, and the negative transformer current $i_{2}$ flows. Substituting $v_{1}^{\prime}=V_{\text {out }}, v_{2}=-V_{\text {out }}$ and the initial current $i_{2}\left(t_{2}\right)=-I_{n}$ into formula (1), the equation regarding the secondary current $i_{2}(t)$ in Mode $2-2$ can be derived as follows:

$$
i_{2}(t)=\frac{2 V_{\text {out }}}{L}\left(t-t_{2}\right)-I_{n}\left(t_{2} \leq t \leq t_{3}\right)
$$

The secondary current $i_{2}(t)$ increases linearly toward zero value, which is shown in Figure 4. Upon the timing $t=t_{3}$, the secondary current $i_{2}(t)$ reaches zero, and Mode $2-2$ is completed. The duration $T_{2}=t_{3}-t_{2}$ of Mode 2-2, is obtained from (13) by the following equation:

$$
T_{2}=t_{3}-t_{2}=\frac{L I_{n}}{2 V_{\text {out }}}
$$

At $i_{2}\left(t_{3}\right)=0$, all four diodes of the secondary rectifier circuit change to turn-off state, and then Mode $2-3$ begins.

In Mode 2-3, the voltages on parallel capacitors $C_{r}$ of diodes $U^{-}$and $V^{+}$are both zero, and the voltages on parallel capacitors $C_{r}$ of diodes $U^{+}$and $V^{-}$are both charged to the output voltage $V_{\text {out }}$ at $t=t_{3}$. The inductor $L$, together with four capacitors $C_{r}$, forms 
an $L C$ resonating circuit and the resonance occurs. Due to the symmetry property of the circuit, the secondary current flow through each pair of capacitors $C_{r}$ with the half value $i_{2} / 2$. Therefore, in Mode $2-3$, the voltage equation is formulated as follows:

$$
v_{1}^{\prime}=L \frac{d i_{2}}{d t}+\frac{2}{C_{r}} \int_{t_{3}}^{t} \frac{i_{2}}{2} d t-V_{\text {out }}
$$

Substituting $v_{1}^{\prime}=V_{\text {out }}$ and $i_{2}\left(t_{3}\right)=0$ into (15), the secondary current $i_{2}(t)$ in the duration $t_{3} \leq t \leq t_{4}$ of Mode $2-3$ is obtained as follows:

$$
i_{2}(t)=2 V_{\text {out }} \sqrt{\frac{C_{r}}{L}} \sin \frac{t-t_{3}}{\sqrt{L C_{r}}}\left(t_{3} \leq t \leq t_{4}\right)
$$

The secondary voltage $v_{2}$ is derived utilizing the secondary current $i_{2}(t)$ in Equation (16) as follows:

$$
v_{2}(t)=v_{1}^{\prime}(t)-L \frac{d i_{2}}{d t}=V_{\text {out }}\left(1-2 \cos \frac{t-t_{3}}{\sqrt{L C_{r}}}\right)
$$

The secondary current $i_{2}$ and voltage $v_{2}$ in (16) and (17) are both sinusoidal waveforms, which are shown in Figure 4 . When the secondary current $i_{2}(t)$ becomes $I_{n}$ and voltage $v_{2}(t)$ becomes $v_{2}(t)=V_{\text {out }}$ at $t=t_{4}$, simultaneously, Mode 2-3 is completed. Because at $t=t_{4}$, the phase angle is $\pi / 2$ as in Figure 4 , the amplitude value $I_{n}$ of the secondary current $i_{2}$ and the duration $T_{3}$ in Mode 2-3 are obtained from (16) and (17) by the following equations:

$$
\begin{gathered}
I_{n}=2 V_{\text {out }} \sqrt{\frac{C_{r}}{L}} \\
T_{3}=t_{4}-t_{3}=\frac{\pi}{2} \sqrt{L C_{r}}
\end{gathered}
$$

The secondary current $i_{2}$ in Mode 2-2 in (13) and duration $T_{2}$ in (14) is applied to Equation (18), and is rewritten in the following equations:

$$
\begin{gathered}
i_{2}(t)=\frac{2 V_{\text {out }}}{L}\left(t-t_{2}-\sqrt{L C_{r}}\right)\left(t_{2} \leq t \leq t_{3}\right) \\
T_{2}=\sqrt{L C_{r}}
\end{gathered}
$$

At $t=t_{4}$, the voltages on the parallel capacitors of the diodes $U^{+}$and $V^{-}$reduce to zero, then the diodes $U^{+}$and $V^{-}$start conducting, and the circuit shifts to Mode 2-4 in Figure 6.

In Mode 2-4, substituting the primary voltage $v_{1}^{\prime}=V_{\text {out }}$, the secondary voltage $v_{2}=V_{\text {out }}$, and the initial value of the secondary current $i_{2}\left(t_{4}\right)=I_{n}$ into (1), in Mode 2-4, the secondary current $i_{2}(t)$ is given by the following equation:

$$
i_{2}(t)=I_{n}=2 V_{\text {out }} \sqrt{\frac{C_{r}}{L}}\left(t_{4} \leq t\right)
$$

The output power $P_{\text {out }}$ is calculated by the average transferring power for the half period $T_{S}$ of the isolated high-frequency transformer using the rectified current $i_{\text {out }}$ in Figure 4:

$$
P_{\text {out }}=\frac{1}{T_{s}} \int_{t_{2}}^{t_{2}+T_{s}} V_{\text {out }} i_{\text {out }} d t=2 V_{\text {out }}^{2} \sqrt{\frac{C_{r}}{L}}\left(1-\frac{1+\pi}{2 T_{s}} \sqrt{L C_{r}}\right)
$$

The effective value of primary current $I_{1}$ is calculated as follows:

$$
I_{1}=\sqrt{\frac{1}{T_{S}} \int_{t_{2}}^{t_{2}+T_{s}} i_{2}^{2} d t}=2 V_{\text {out }} \sqrt{\frac{C_{r}}{L}\left\{1-\left(\frac{2}{3}+\frac{\pi}{4}\right) \frac{\sqrt{L C_{r}}}{T_{s}}\right\}}
$$


Substituting (23), (24), and $V_{1}=V_{\text {out }}$, into (9), the total power factor TPF is obtained as follows:

$$
T P F=\frac{1-\frac{1+\pi}{2 T_{s}} \sqrt{L C_{r}}}{\sqrt{1-\left(\frac{2}{3}+\frac{\pi}{4}\right) \frac{\sqrt{L C_{r}}}{T_{S}}}}
$$

\subsection{Output Power Control by Frequency Variation}

Under the condition of the unity input and output voltage conversion ratio $M_{v}=$ $1\left(V_{\text {in }}=V_{\text {out }}\right)$, the output power $P_{\text {out }}$ in (23) is a function of the half period $T_{S}$ of the highfrequency transformer. If the half period $T_{S}$ is shorter than that in Figure 4 , the duration of Mode 2-4 is shorter and the output power $P_{\text {out }}$ decreases. The output power $P_{\text {out }}$ can be controlled by the transformer frequency $f_{s}$ given by the following equation:

$$
f_{s}=\frac{1}{2 T_{s}}
$$

The resonant frequency $f_{o}$ in the circuit is given in (27):

$$
f_{o}=\frac{1}{2 \pi \sqrt{L C_{r}}}
$$

Substituting (26) and (27) into (23), the output power $P_{\text {out }}$ is rewritten as a function of the frequency ratio $f_{s} / f_{o}$ as follows:

$$
P_{\text {out }}=2 V_{\text {out }}^{2} \sqrt{\frac{C_{r}}{L}}\left\{1-\left(\frac{1}{2}+\frac{1}{2 \pi}\right) \frac{f_{s}}{f_{o}}\right\}
$$

Figure 7 shows the characteristics of the output power $P_{\text {out }}$ with respect to the frequency ratio $f_{s} / f_{o}$ based on (28). The resonant frequency is determined by the circuit parameters and is a constant value.

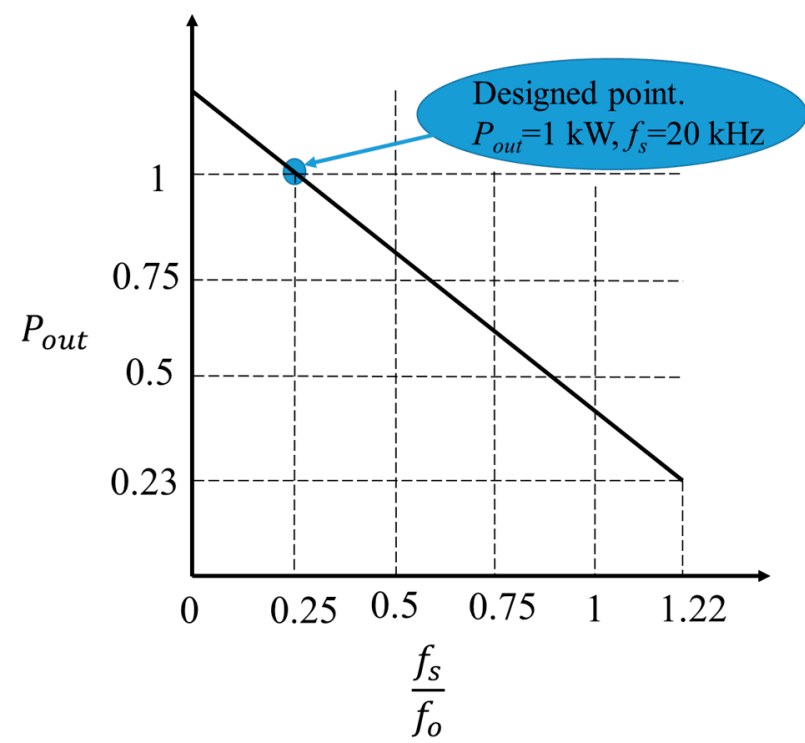

Figure 7. Output power characteristic with respect to the switching frequency of the transformer.

By increasing the transformer frequency $f_{s}$, the output power $P_{\text {out }}$ can be reduced. In Figure 7 , the output power is notarized as $P_{\text {out }}=1$ at the frequency ratio $\left(f_{s} / f_{o}\right)=1 / 4$. The maximum frequency ratio $\left(f_{s} / f_{o}\right)_{\text {max }}$ is the condition in which the duration of Mode $2-4$ in 
Figure 4 is zero. Because it means $T_{s}=T_{2}+T_{3}$, the maximum frequency ratio $\left(f_{s} / f_{o}\right)_{\max }$ is given by the following equation:

$$
\left(\frac{f_{s}}{f_{o}}\right)_{\max }=\frac{2 \pi \sqrt{L C_{r}}}{2\left(T_{2}+T_{3}\right)}=\frac{2 \pi}{2+\pi}=1.22
$$

The highest transformer frequency satisfying the output power $P_{\text {out }}$ of $(28)$ is $\left(f_{s} / f_{o}\right)_{\max }=1.22$. In Figure 7 , the output power $P_{\text {out }}$ at $\left(f_{s} / f_{o}\right)_{\max }=1.22$ can be reduced to 0.23 of the rated output power $P_{\text {out }}=1$. When the frequency ratio is higher than $\left(f_{s} / f_{o}\right)_{\max }=1.22$, the output power $P_{\text {out }}$ can be reduced further than that in (28).

\section{Design of Circuit Parameters}

The design and calculation method for the circuit parameters of the proposed SR-SAB converter are introduced here. Table 3 shows the specifications and designed parameters of the proposed SR-SAB converter in a laboratory experimental system. The SR-SAB converter is designed with the rated specifications of output power $P_{\text {out }}=1 \mathrm{~kW}$, output voltage $V_{\text {out }}=48 \mathrm{~V}$, input voltage $V_{\text {in }}=265 \mathrm{~V}$, transformer frequency $f_{s}=20 \mathrm{kHz}$, and frequency ratio $f_{s} / f_{o}=1 / 4$. The turn ratio of the high-frequency transformer $a$ is equal to the ratio of the input and output voltages, as seen below:

$$
a=\frac{V_{\text {in }}}{V_{\text {out }}}=5.5
$$

Table 3. Specifications and designed parameters of proposed SR-SAB converter.

\begin{tabular}{cc}
\hline (A) Rated specifications. & \\
Output power $P_{\text {out }}$ & $1 \mathrm{~kW}$ \\
Output voltage $V_{\text {out }}$ & $48 \mathrm{~V}$ \\
$\quad$ Input voltage $V_{\text {in }}$ & $265 \mathrm{~V}$ \\
Transformer frequency $f_{s}$ & $20 \mathrm{kHz}$ \\
Frequency ratio $f_{s} / f_{o}$ & $1 / 4$ \\
\hline (B) Designed parameters. & \\
$\quad$ Turns ratio $a$ & 5.5 \\
Leakage inductance $L$ & $7.7 \mu \mathrm{H}$ \\
Resonant capacitor $C_{r}$ & $520 \mathrm{nF}$ \\
Soft-switching capacitor $C_{s}$ & $1 \mathrm{nF}$ \\
DC capacitors $C_{1}, C_{2}$ & $1500 \mu \mathrm{F}$ \\
\hline
\end{tabular}

Because transformer frequency is selected as $f_{s}=20 \mathrm{kHz}$, the half-cycle period $T_{s}$, resonant frequency $f_{0}$, and resonant angular frequency $1 / \sqrt{L C_{r}}$ are given in the following equations:

$$
\begin{gathered}
T_{s}=\frac{1}{2 f_{s}}=25 \mu \mathrm{s} \\
f_{o}=4 f_{s}=80 \mathrm{kHz} \\
\frac{1}{\sqrt{L C_{r}}}=2 \pi f_{o} \simeq 5.0 \times 10^{5} \mathrm{rad} / \mathrm{s}
\end{gathered}
$$

The duration $T_{2}$ of Mode 2-2 in (21) and the duration $T_{3}$ of Mode 2-3 in (19) are calculated as (34) and (35), respectively.

$$
\begin{gathered}
T_{2}=\sqrt{L C_{r}}=2.0 \mu \mathrm{s} \\
T_{3}=\frac{\pi}{2} \sqrt{L C_{r}}=3.14 \mu \mathrm{s}
\end{gathered}
$$


The amplitude $I_{n}$ of the secondary current $i_{2}$ is obtained from (18) and (23) as follows:

$$
I_{n}=2 V_{\text {out }} \sqrt{\frac{C_{r}}{L}}=\frac{P_{\text {out }}}{V_{\text {out }}\left(1-\frac{1+\pi}{2 T_{s}} \sqrt{L C_{r}}\right)}=25 \mathrm{~A}
$$

From (36), the characteristic impedance $\sqrt{L / C_{r}}$ is obtained the following equation:

$$
\sqrt{\frac{L}{C_{r}}}=\frac{2 V_{\text {out }}}{I_{n}}=3.84 \Omega
$$

From (33) and (37), the leakage inductance $L$ and resonant capacitor $C_{r}$ are determined:

$$
\begin{gathered}
L=\sqrt{L C_{r}} \sqrt{\frac{L}{C_{r}}}=7.7 \mu \mathrm{H} \\
C_{r}=\sqrt{L C_{r}} \sqrt{\frac{C_{r}}{L}}=0.52 \mu \mathrm{F}
\end{gathered}
$$

Regarding to the primary H-bridge converter of Mode 1-2 in Figure 5, each softswitching capacitor $C_{s}$ is changed between 0 and voltage $V_{i n}$. Half of the primary current $i_{1}\left(=I_{n} / a\right)$ flows to the capacitor. Therefore, the duration $T_{12}$ of Mode $1-2$ is obtained as follows:

$$
T_{12}=\frac{C_{s} V_{i n}}{I_{n} / 2 a}
$$

By giving the duration $T_{12}=0.1 \mu$ s of Mode $1-2$, the soft switching capacitor $C_{s}$ is designed as follows:

$$
C_{s}=\frac{I_{n} T_{12}}{2 a V_{\text {in }}}=0.8 \times 10^{-9} \simeq 1 \mathrm{nF}
$$

In order to compare them with the characteristics in Table 2, the characteristics of the proposed SR-SAB converter at unity turn ratio $a=1$ are calculated. The effective values of the primary current $I_{1}=23.5 \mathrm{~A}$ in (24) and the total power factor $T P F=0.89$ in (25) are obtained using $V_{\text {out }}=48 \mathrm{~V}$, the leakage inductance $L$ in (38), and the resonant capacitor $C_{r}$ in (39). As mentioned in Section 2, the proposed SR-SAB converter can operate at a voltage conversion ratio $M_{v}=1.0$, and the peak current and total power factor TPF in Table 2 show significant improvement compared with those of the conventional SAB converter.

\section{Experimental Results}

The operation and behavior of the $1 \mathrm{~kW}, 265 \mathrm{~V} / 48 \mathrm{~V} \mathrm{SR}-\mathrm{SAB}$ converter described in Table 3 is verified by experimental waveforms. The primary H-bridge is composed of four Rohm SCT3022AL SiC MOSFETs, and the secondary diode bridge is composed of four VS-100BGQ100 Schottky diodes. The inductor value $L=7.7 \mu \mathrm{H}$ is derived from the leakage inductance of the high-frequency transformer. Furthermore, the resonant capacitor $C_{r}$ is composed of one $330 \mathrm{nF}$ and two $100 \mathrm{nF}$ film capacitors in parallel. The dead time $T_{\text {dead }}=0.2 \mu$ s of the primary switches is used in the experimental circuit.

Figure 8a shows the experimental set up of the proposed SR-SAB DC-DC converter. The DC input source $V_{\text {in }}=265 \mathrm{~V}$ is obtained from the three-phase full-bridge diode rectifier circuit from the three-phase supply voltages of $60 \mathrm{~Hz}$ and $200 \mathrm{~V}$, while the $48 \mathrm{~V}$ DC load is the regenerative dc power supplier, pCUBE. The controller is the PE-Expert 4 system using DSP TMS320C6657, and the DL850 Yokogawa is used for measuring the voltage and current waveforms. Finally, Xviewer displaying software is used for displaying the voltage and current waveforms directly from the DL850.

Figure $8 \mathrm{~b}$ shows the electrical diagram of the proposed SR-SAB DC-DC converter with the detailed descriptions of the circuit that has been presented above in Figure 8 a. 


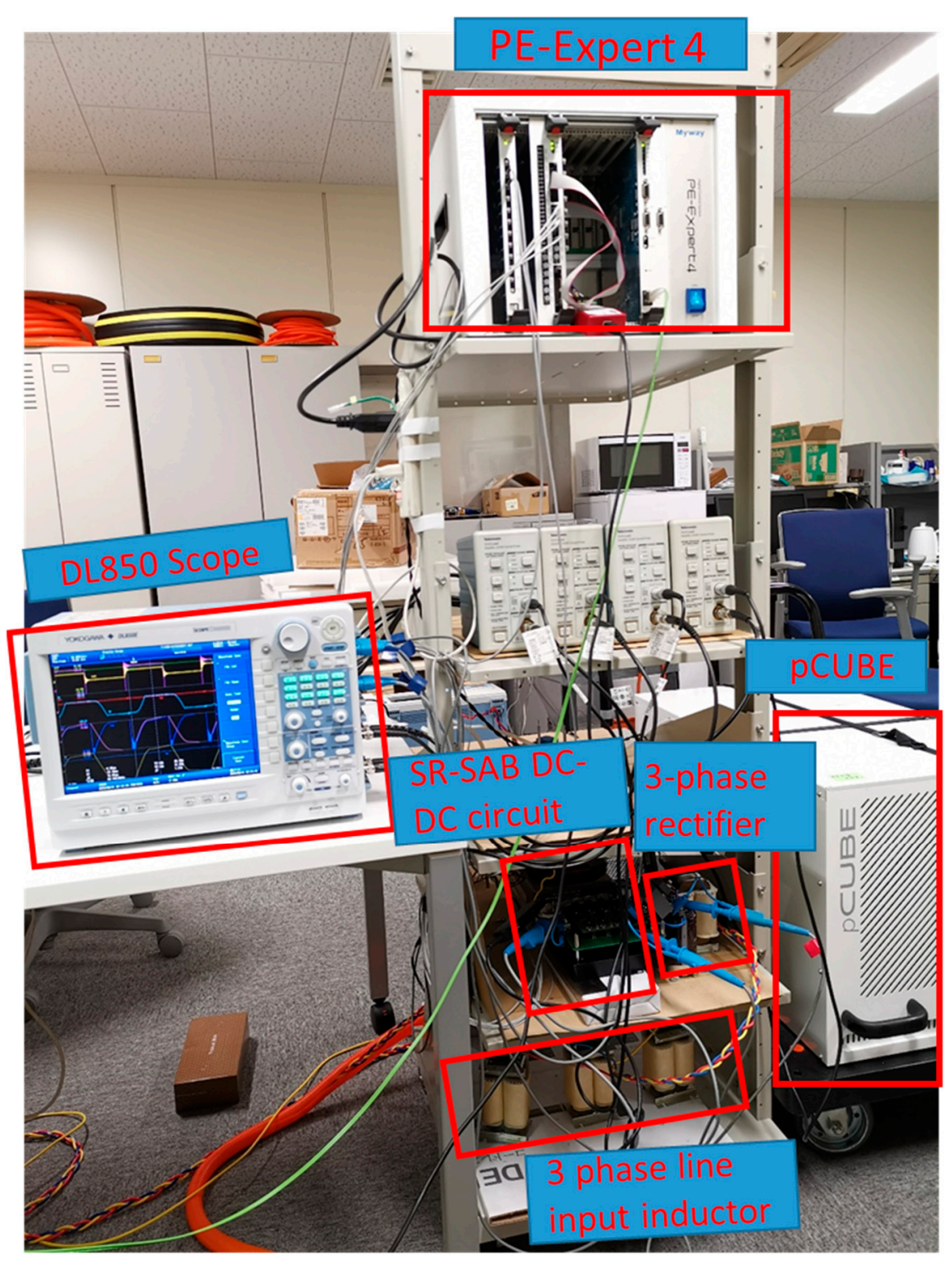

(a)

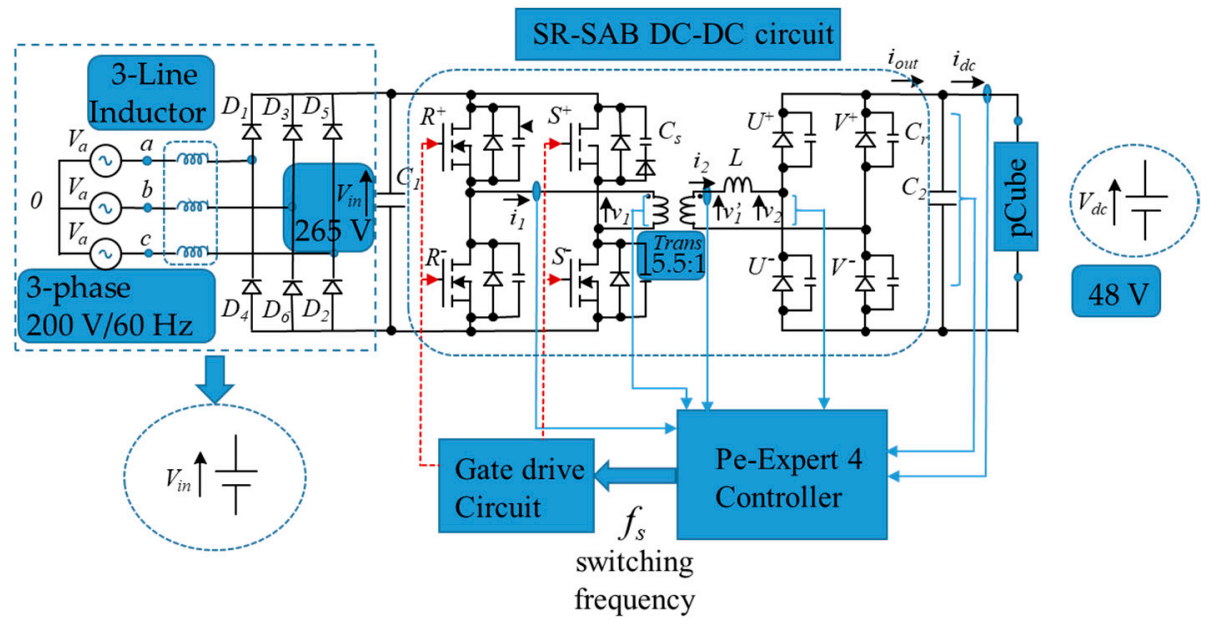

(b)

Figure 8. (a) Proposed SR-SAB DC-DC 265VDC/48VDC converter experimental setup; (b) Proposed SR-SAB DC-DC 265VDC/48VDC converter electrical diagram. 
Figure 9 shows the experimental voltage and current waveforms during two periods of the high-frequency transformer at $f_{s}=20 \mathrm{kHz}$. The sequential waveforms are the gate driving signal $v_{g}$ of the switch $R^{+}$, primary H-bridge voltage $v_{1}$, transformer secondary side voltages $v_{2}$, output DC voltage $V_{\text {out }}$, secondary side current $i_{2}$, and output DC current $i_{d c}$. The gate signal $v_{g}$ and the half period $T_{s}=25 \mu$ s generates the primary H-bridge voltage $v_{1}$ with the amplitude $V_{i n}=265 \mathrm{~V}$ and switching frequency $f_{s}=20 \mathrm{kHz}$. The secondary rectangular waveform voltage $v_{2}$ is also observed. The secondary current $i_{2}$ flows in the circuit according to the difference in the phase-shift angle between $v_{1}^{\prime}$ and $v_{2}$. The amplitude $I_{n}$ of the secondary current $i_{2}$ is at the designed value of $25 \mathrm{~A}$. The duration $T_{2}=2 \mu$ s of Mode 2-2 in (34) and $T_{3}=3.14 \mu$ s of Mode 2-3 in (35) are obtained. The average output DC current $i_{d c}$ is $21 \mathrm{~A}$. All the experimental waveform results are similar to the theoretical results.

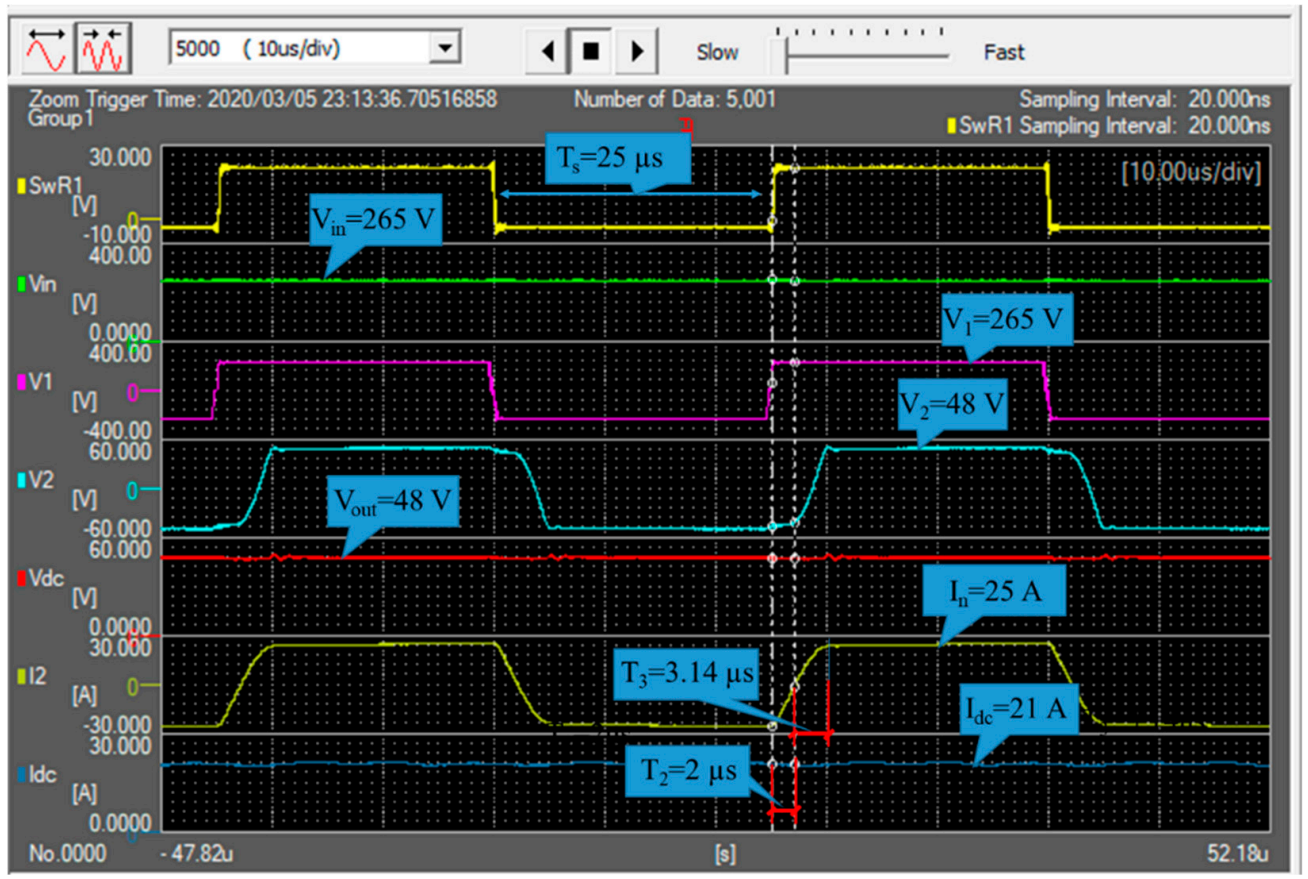

Figure 9. Experimental voltage and current waveforms at $f_{s}=20 \mathrm{kHz}$.

Figure 10 shows the experimental voltage and current waveforms of the isolated highfrequency transformer at $f_{s}=80 \mathrm{kHz}$. The order of the waveforms shown in Figure 10 is the same as that in Figure 9. The gate driving signal $v_{g}$ with the half period $T_{S}=6.25 \mu \mathrm{s}$ generates the primary $\mathrm{H}$-bridge voltage $v_{1}$ with the amplitude $V_{\text {in }}=265 \mathrm{~V}$ and the switching frequency $f_{s}=80 \mathrm{kHz}$. The amplitude $I_{n}$ of the secondary current $i_{2}=25 \mathrm{~A}$, while the duration $T_{2}=2 \mu$ s of Mode 2-2 in (34) and $T_{3}=3.14 \mu$ s of Mode 2-3 in (35) are the same as in Figure 9. The duration of Mode 2-4 is shorter than that in Figure 9. As a result, the average output DC current $i_{d c}$ is reduced to $8.75 \mathrm{~A}$. 


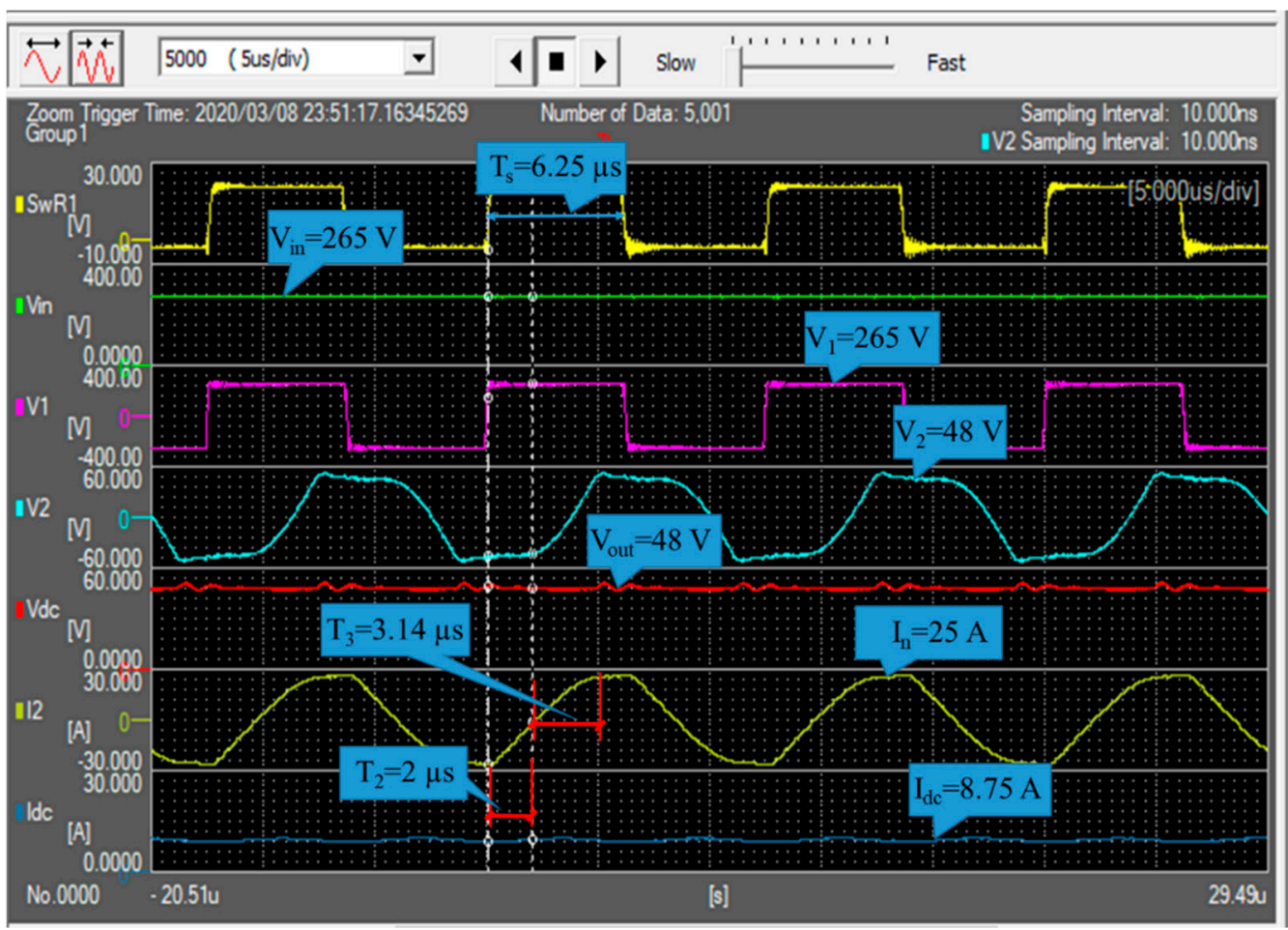

Figure 10. Experimental voltage and current waveforms at $f_{s}=80 \mathrm{kHz}$.

Figure 11 shows the experimental voltage and current waveforms of the isolated high-frequency transformer at $f_{s}=100 \mathrm{kHz}$. The order of the waveforms shown in Figure 11 is the same as that in Figure 9. The gate driving signal $v_{g}$ with the half period $T_{S}=5 \mu$ s generates the primary $\mathrm{H}$-bridge voltage $v_{1}$ with the amplitude $V_{\text {in }}=265 \mathrm{~V}$ and the switching frequency $f_{s}=100 \mathrm{kHz}$. The amplitude $I_{n}$ of secondary current $i_{2}=25 \mathrm{~A}$, while the duration $T_{2}=2 \mu$ s of Mode 2-2 in (34) and also $T_{3}=3.14 \mu$ s of Mode 2-3 in (35) are the same as in Figure 10. The duration of Mode 2-4 is shorter than that in Figure 10. As a result, the average output DC current $i_{d c}$ is reduced to $4.6 \mathrm{~A}$.

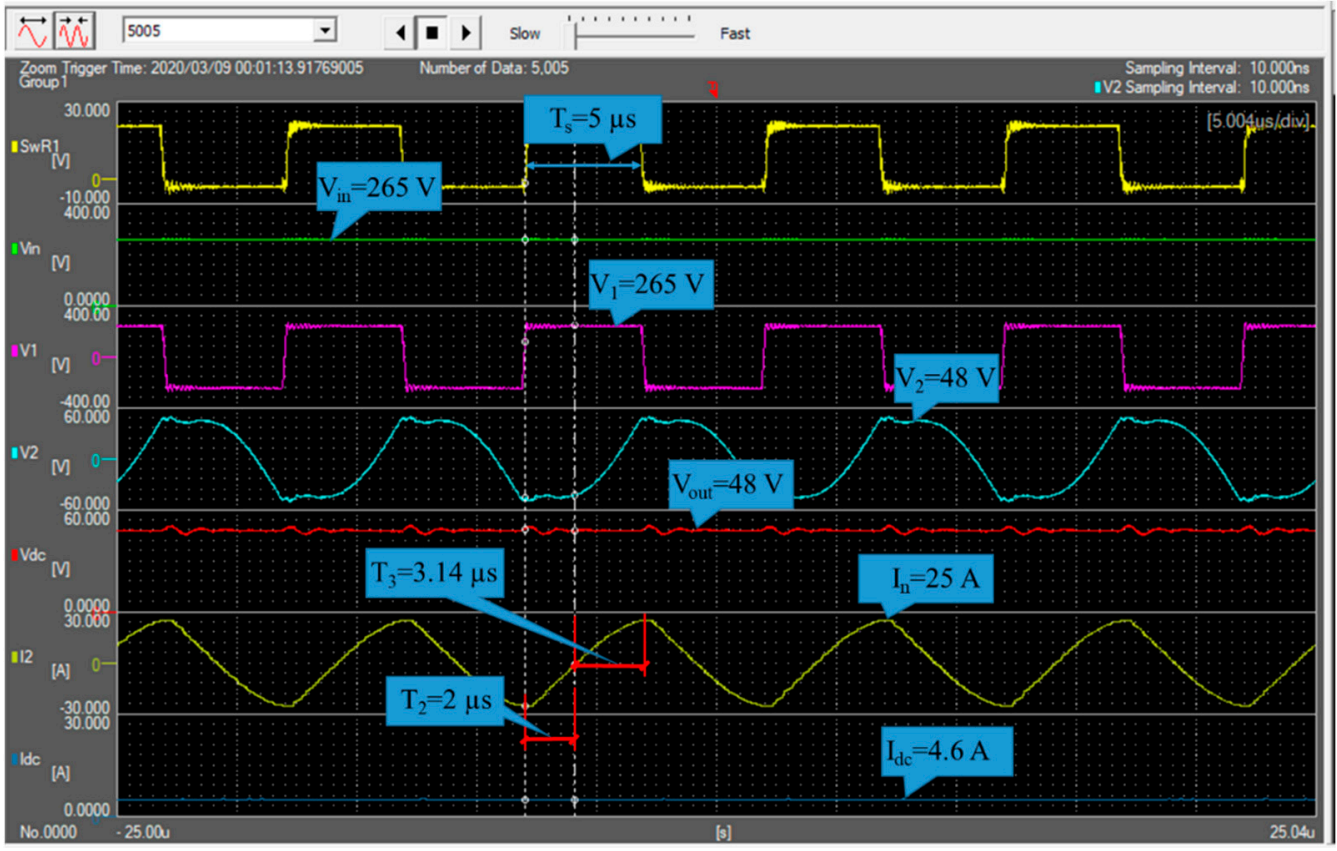

Figure 11. Experimental voltage and current waveforms at $f_{s}=100 \mathrm{kHz}$. 
Figure 12 shows the experimental voltage and current waveforms during two and a half periods of the high-frequency transformer at $f_{s}=5 \mathrm{kHz}$. The order of the waveforms shown in Figure 12 is the same as that in Figure 9. The gate signal $v_{g}$ with the half period $T_{S}=100 \mu$ s generates the primary H-bridge voltage $v_{1}$ with the amplitude $V_{\text {in }}=265 \mathrm{~V}$ and switching frequency $f_{s}=5 \mathrm{kHz}$. The secondary rectangular waveform voltage $v_{2}$ is observed. The secondary current $i_{2}$ flows in the circuit according to the difference in the phase-shift angle between $v_{1}^{\prime}$ and $v_{2}$. The amplitude $I_{n}$ of the secondary current $i_{2}$ is at the designed value of $25 \mathrm{~A}$. The total duration $T_{2}+T_{3}=5.14 \mu \mathrm{s}$ is obtained, while the duration $T_{2}=2 \mu$ s of Mode 2-2 in (34) and $T_{3}=3.14 \mu$ s of Mode 2-3 in (35) are achieved in the same way as in Figure 9. The average output DC current $i_{d c}$ is $24.7 \mathrm{~A}$. As can be seen from Figure 12, a very high TPF experimental value can be achieved in this case for SR-SAB compared to the calculated theoretical value $(T P F=0.97)$.

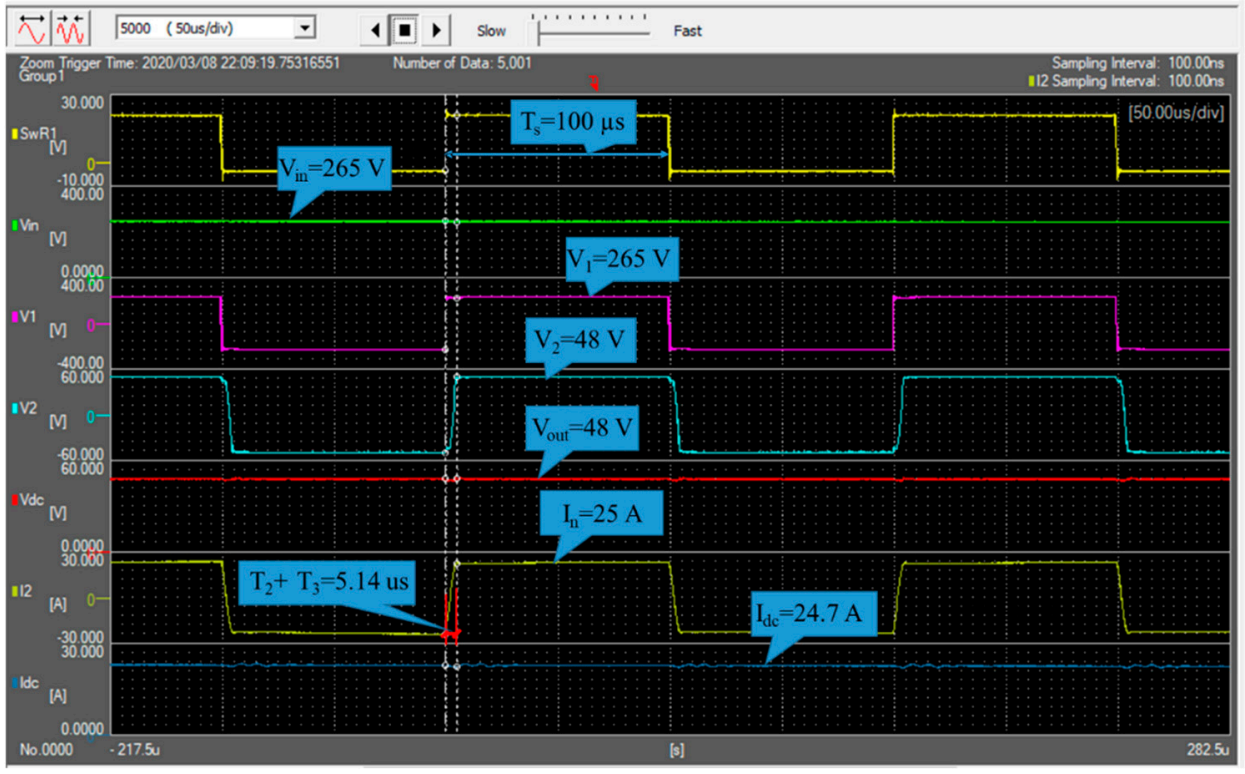

Figure 12. Experimental voltage and current waveforms at $f_{s}=5 \mathrm{kHz}$.

With all the experimental voltage and current waveforms, no high peak stress on the primary and secondary sides is observed as it is in some cases of the normal $L C$ resonant circuit. The overshoot values of primary and secondary voltage in all cases are within the range of 5 10 percent, which is normal, and which is in fact another advantage of this topology because switching devices and capacitors can be selected that are small enough to reduce the overall size.

Figure 13 shows the experimental characteristics of the output power $P_{\text {out }}$ versus the frequency ratio $f_{s} / f_{o}$. When the transformer frequency $f_{s}$ varies from $5 \mathrm{kHz}$ to $100 \mathrm{kHz}$, the output power $P_{\text {out }}$ gradually decreases from $1185 \mathrm{~W}$ to $220 \mathrm{~W}$, and the characteristics coincide with the theoretical linear line in (28). The output power $P_{\text {out }}$ can be regulated over a wide range by adjusting the frequency ratio $f_{s} / f_{o}$ from 0 to 1.22 . 


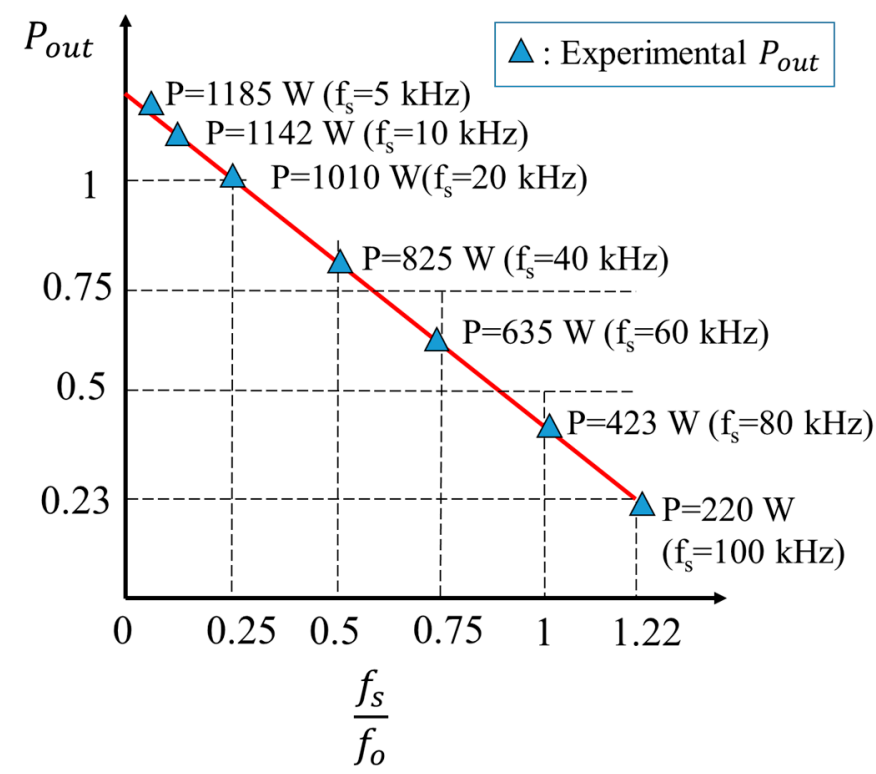

Figure 13. Characteristics of output power $P_{\text {out }}$ versus switching frequency ratio $f_{s} / f_{o}$.

Figure 14 shows the efficiency of the converter for the output power range. The input as well as output electrical powers are both measured using a power analyzer (WT1800, YOKOGAWA). A maximum efficiency of $97.33 \%$ is achieved at $P_{\text {out }}=1185 \mathrm{~W}$ with the transformer frequency $f_{s}=5 \mathrm{kHz}$. At the rated output power $P_{\text {out }}=1 \mathrm{~kW}$ and the transformer frequency $f_{s}=20 \mathrm{kHz}$, the measured efficiency of the circuit is $95.8 \%$. At a low output power $P_{\text {out }}=220 \mathrm{~W}$ at $f_{s}=100 \mathrm{kHz}$, the efficiency is $90.2 \%$. When the transformer frequency $f_{s}$ increases from $5 \mathrm{kHz}$ to $100 \mathrm{kHz}$, the efficiency decreases owing to the reduction in the output power and the increase in the switching loss and iron loss of the transformer with a higher transformer frequency.

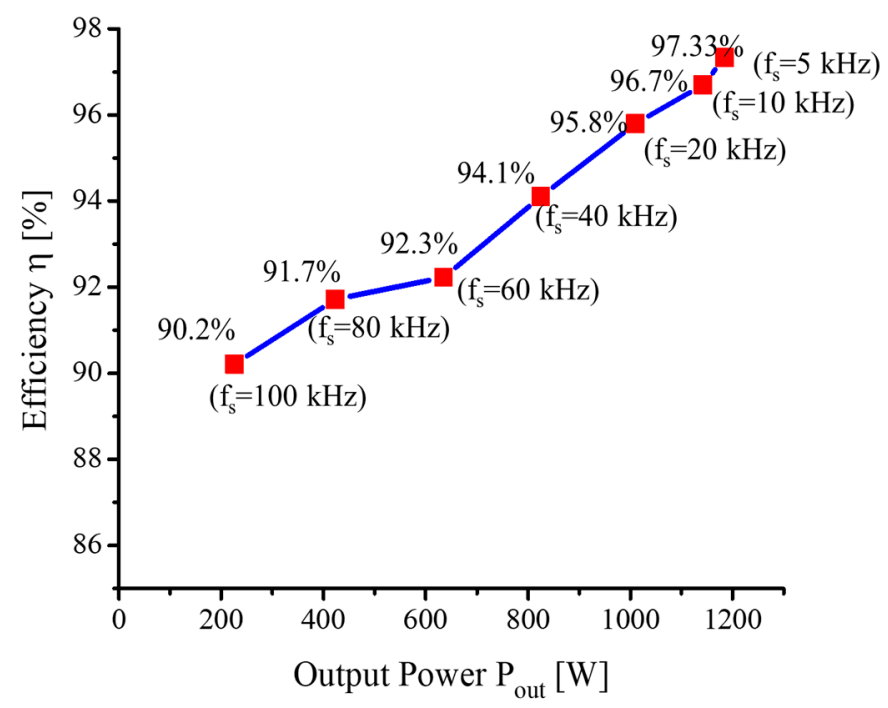

Figure 14. Efficiency versus output power characteristic.

\section{Conclusions}

This paper presented a unidirectional SR-SAB DC-DC converter, in which the resonant capacitor $C_{r}$ connected to each diode in parallel in the secondary circuit of the SAB converter. The SR-SAB DC-DC converter achieves the unity DC voltage conversion ratio and improves the total power factor (TPF) of the transformer and the series resonance between inductor $L$ and resonant capacitor $C_{r}$ compared with the conventional SAB converter. 
The overshoot value of the primary and secondary voltage is not significant, meaning that it is an advantage to select smaller rating devices. The soft-switching commutations in the primary H-bridge and secondary diode bridge are achieved. The behavior analysis and circuit parameter design of the proposed SR-SAB DC-DC converter were clarified. A control method for the output power using the transformer frequency was proposed. The characteristics of the proposed converter were verified by theory and experimental results using a laboratory prototype with an output power of $1 \mathrm{~kW}$, transformer frequency of $20 \mathrm{kHz}$, and output DC voltage of $48 \mathrm{~V}$.

Author Contributions: Conceptualization, T.T.; methodology, T.T.; software, C.A.T.; validation, T.T. and C.A.T.; formal analysis, C.A.T.; investigation, C.A.T.; resources, T.T.; data curation, C.A.T.; writing-original draft preparation, C.A.T.; writing-review and editing, T.T. and C.A.T.; visualization, C.A.T.; supervision, T.T.; funding acquisition, T.T. All authors have read and agreed to the published version of the manuscript.

Funding: This work was supported and funded in part by JSPS KAKENHI Grant Number JP21H01310.

Institutional Review Board Statement: Not applicable.

Informed Consent Statement: Not applicable.

Data Availability Statement: Not applicable.

Conflicts of Interest: The authors declare no conflict of interest.

\section{References}

1. Doncker, R.W.D.; Divan, D.M.; Kheraluwala, M.H. A Three Phase Soft-Switched High-Power-Density DC/DC Converter for High-Power Applications. IEEE Trans. Ind. Appl. 1991, 27, 63-73. [CrossRef]

2. Kheraluwala, M.H.; Gascoigne, R.W.; Divan, D.M.; Baumann, E.D. Performance Characterization of a High-Power Dual Active Bridge DC to DC Converter. IEEE Trans. Ind. Appl. 1992, 28, 1294-1301. [CrossRef]

3. Zhao, B.; Song, Q.; Liu, W.; Sun, Y. Overview of Dual-Active-Bridge Isolated Bidirectional DC-DC Converter for High FrequencyLink Power-Conversion System. IEEE Trans. Power Electron. 2014, 29, 4091-4106. [CrossRef]

4. Haneda, R.; Akagi, H. Design and Performance of the 850-V 100-kW 16-kHz Bidirectional Isolated DC-DC Converter Using SiC-MOSFET/SBD H-Bridge Modules. IEEE Trans. Power Electron. 2020, 35, 10013-10025. [CrossRef]

5. bin Ab Malek, M.H.A.; Kakigano, H.; Takaba, K. Dual Active Bridge DC-DC Converter with Tunable Dual Pulse-Width Modulation for Complete Zero Voltage Switching Operation. IEEJ J. Ind. Appl. 2019, 8, 98-107.

6. Ramachandran, R.; Nymand, M. Experimental Demonstration of a 98.8\% Efficient Isolated DC-DC GaN Converter. IEEE Trans. Ind. Electron. 2017, 64, 9104-9113. [CrossRef]

7. Yamanaka, H.; Yamada, H. Dual Active Bridge DCDC Converter based Wide Dimming Range LED Driver with HighSpeed Turn-Off for High-Brightness LED Floodlight. IEEJ J. Ind. Appl. 2019, 8, 556-557. [CrossRef]

8. Hong, T.; Geng, Z.; Qi, K.; Zhao, X.; Ambrosio, J.; Gu, D. A Wide Range Unidirectional Isolated DC-DC Converter for Fuel Cell Electric Vehicles. IEEE Trans. Ind. Electron. 2021, 68, 5932-5943. [CrossRef]

9. Sha, D.; Zhang, J.; Sun, T. Multimode Control Strategy for SiC Mosfets Based Semi-Dual Active Bridge DC-DC Converter. IEEE Trans. Power Electron. 2019, 34, 5476-5486. [CrossRef]

10. Haneda, R.; Akagi, H.; Hukuda, K. Output Voltage Regulation of a Unidirectional Isolated DC-DC Converter Used as an Auxiliary Power Supply for Electric Commuter Trains. IEEJ Trans. IA 2017, 137, 406-413. [CrossRef]

11. Mweene, L.H.; Wright, C.A.; Schlecht, M.F. A 1 kW 500 kHz Front-End Converter for A Distributed Power Supply System. IEEE Trans. Power Electron. 1991, 6, 398-407. [CrossRef]

12. Singh, S.A.; Ronanki, D.; Praneeth, A.V.J.S.; Williamson, S.S. State-of-the-art Charging Solutions for Electric Transportation and Autonomous E-mobility. J. Renew. Energy Sustain. Dev. (RESD) 2018, 4. [CrossRef]

13. Fontana, C.; Forato, M.; Kumar, K.; Outeiro, M.T.; Bertoluzzo, M.; Buja, G. Soft-switching capabilities of SAB vs. DAB converters. IECON2015-Yokohama 2015, 3485-3490. [CrossRef]

14. Ting, Y.; de Haan, S.; Ferreira, J.A. The Partial-Resonant Single Active Bridge DC-DC Converter for Conduction Losses Reduction in the Single Active Bridge. 2013 IEEE ECCE Asia Downunder 2013, 987-993. [CrossRef]

15. Awwad, A.E.; Badawi, N.; Dieckerhoff, S. Efficiency analysis of a high frequency PS-ZVS isolated unidirectional full-bridge DC-DC converter based on SiC MOSFETs. In Proceedings of the 18th European Conference on Power Electronics and Applications (EPE'16 ECCE Europe), Karlsruhe, Germany, 5-8 September 2016; pp. 1-10.

16. Max, L.; Thiringer, T. Control method and snubber selection for a $5 \mathrm{MW}$ wind turbine single active bridge DC/DC converter. In Proceedings of the 2007 European Conference on Power Electronics and Applications, Aalborg, Denmark, 2-5 September 2007; pp. 1-10. 
17. Park, K.; Chen, Z. Analysis and design of a parallel-connected single active bridge DC-DC converter for high-power wind farm applications. In Proceedings of the 2013 European Conference on Power Electronics and Applications, Lille, France, 2-6 September 2013; pp. 1-10.

18. Tuan, C.A.; Naoki, H.; Takeshita, T. Unidirectional Isolated High-Frequency-Link DC-DC Converter Using Soft Switching Technique. In Proceedings of the 2019, 4th IEEE International Future Energy Electronics Conference (IFEEC), Singapore, 25-28 November 2019; pp. 595-600. 